\title{
Investigation of Light Scattering by Ocean Waters
}

\author{
Robert A. Maffione \\ Hydro-Optics, Biology, and Instrumentation Laboratories \\ P.O. Box 859 \\ Moss Landing, California 95039 \\ Phone: (831) 884-9409 Fax: (831) 884-9411 Email: maffione@ hobilabs.com
}

Award Number: N0001401C0075

http://www.hobilabs.com

\section{LONG-TERM GOALS}

Our overall, long-term goal is to significantly advance our understanding of the light scattering properties of marine particles as well as their general optical properties. Our goal is to study particle optical properties using a unique set of new optical instruments that we have developed on previous ONR funded projects. Observational studies will be conducted at sea in various coastal waters, and careful laboratory experiments of particle optical properties will be performed. This project is currently in its first year.

\section{OBJECTIVES}

All of the instruments required for us to carry out a thorough investigation of light scattering by marine particles, both in situ and benchtop, are now in our possession, having been developed on a previous ONR funded project (see the annual report, "Light Scattering Properties and Processes of Coastal Waters). We thus propose to address the following major questions in this research program. We expect, of course, that new or related questions will arise in the course of this research and will be addressed as needed. Accordingly, the basic objectives, or problems we seek to address are:

1. What is the range of variability in the shape of the VSF (i.e., the scattering phase function) for oceanic waters, especially coastal waters? How does the phase function relate to other optical property measurements, the nature of the particles, and biological properties such as chlorophyll concentration? And most basically, what are the phase functions for the various endmember classes of marine particles (e.g., phytoplankton, organic and inorganic detritus, sediments, etc.)?

2. How accurate and robust is the conversion to estimate the backscattering coefficient from a measurement of the VSF at a nominal angle in the backward direction? In other words, how variable is $\chi$ in the equation $b_{b}=2 \pi \chi \beta\left(\psi_{0}\right)$, where $\beta\left(\psi_{0}\right)$ is the nominal-angle measurement of the VSF (for the HydroScat, $\psi_{0}=140$ degrees)?

3. How well can Mie theory be used to calculate the VSF of marine particles based on their measured size distributions with a Coulter Counter? Does the estimated complex index of refraction for obtaining the best match with VSF measurements match the refractive index inferred from that traditional approach of using spectral absorption and beam attenuation measurements (e.g., Bricaud, Morel and Prieur [1983])? 


\section{Report Documentation Page}

Form Approved

OMB No. 0704-0188

Public reporting burden for the collection of information is estimated to average 1 hour per response, including the time for reviewing instructions, searching existing data sources, gathering and maintaining the data needed, and completing and reviewing the collection of information. Send comments regarding this burden estimate or any other aspect of this collection of information,

including suggestions for reducing this burden, to Washington Headquarters Services, Directorate for Information Operations and Reports, 1215 Jefferson Davis Highway, Suite 1204, Arlington

VA 22202-4302. Respondents should be aware that notwithstanding any other provision of law, no person shall be subject to a penalty for failing to comply with a collection of information if it

does not display a currently valid OMB control number.

\begin{tabular}{|c|c|c|}
\hline $\begin{array}{l}\text { 1. REPORT DATE } \\
\mathbf{3 0} \text { SEP } 2001\end{array}$ & 2. REPORT TYPE & $\begin{array}{l}\text { 3. DATES COVERED } \\
\mathbf{0 0 - 0 0 - 2 0 0 1} \text { to } 00-\mathbf{0 0 - 2 0 0 1}\end{array}$ \\
\hline \multirow{3}{*}{\multicolumn{2}{|c|}{$\begin{array}{l}\text { 4. TITLE AND SUBTITLE } \\
\text { Investigation of Light Scattering by Ocean Waters }\end{array}$}} & 5a. CONTRACT NUMBER \\
\hline & & 5b. GRANT NUMBER \\
\hline & & 5c. PROGRAM ELEMENT NUMBER \\
\hline \multirow{3}{*}{\multicolumn{2}{|c|}{ 6. AUTHOR(S) }} & 5d. PROJECT NUMBER \\
\hline & & 5e. TASK NUMBER \\
\hline & & 5f. WORK UNIT NUMBER \\
\hline \multicolumn{2}{|c|}{$\begin{array}{l}\text { 7. PERFORMING ORGANIZATION NAME(S) AND ADDRESS(ES) } \\
\text { Hydro-Optics, Biology, and Instrumentation Laboratories,,P.O. Box } \\
\text { 859,,Moss Landing,,CA, } 95039\end{array}$} & $\begin{array}{l}\text { 8. PERFORMING ORGANIZATION } \\
\text { REPORT NUMBER }\end{array}$ \\
\hline \multirow{2}{*}{\multicolumn{2}{|c|}{ 9. SPONSORING/MONITORING AGENCY NAME(S) AND ADDRESS(ES) }} & 10. SPONSOR/MONITOR'S ACRONYM(S) \\
\hline & & $\begin{array}{l}\text { 11. SPONSOR/MONITOR'S REPORT } \\
\text { NUMBER(S) }\end{array}$ \\
\hline
\end{tabular}

12. DISTRIBUTION/AVAILABILITY STATEMENT

Approved for public release; distribution unlimited

13. SUPPLEMENTARY NOTES

14. ABSTRACT

Our overall, long-term goal is to significantly advance our understanding of the light scattering properties of marine particles as well as their general optical properties. Our goal is to study particle optical properties using a unique set of new optical instruments that we have developed on previous ONR funded projects. Observational studies will be conducted at sea in various coastal waters, and careful laboratory experiments of particle optical properties will be performed. This project is currently in its first year.

15. SUBJECT TERMS

16. SECURITY CLASSIFICATION OF:

a. REPORT

unclassified b. ABSTRACT unclassified c. THIS PAGE unclassified
17. LIMITATION OF ABSTRACT

Same as Report (SAR)
18. NUMBER OF PAGES

19a. NAME OF RESPONSIBLE PERSON

7 
4. What are the particles and processes responsible for the shapes and magnitudes of the VSF? For example: Is turbulence responsible for the slope of the VSF near 0 degrees? Are submicron particles the chief source of optical backscattering? Does near-forward scattering depend chiefly on the particle size, as opposed to their shape and/or refractive index?

5. In terms of instrument closure, how consistent are comparisons of various optical properties measured with different instruments and methods? What are the greatest sources of errors and how can they be improved? In terms of model closure, how well do radiative transfer calculations actually match measured AOP's when using measured IOP's as input? Again, what are the greatest sources of errors under various conditions and how can they be improved? In terms of inverse problems, how does the measured VSF, vis a vis measurements of concomitant optical properties, affect inverse relationships such as those between IOP's and AOP's?.

\section{APPROACH}

We will carry out an extensive program of both field and laboratory research on the nature of light scattering by ocean waters and their constituent particles. This research will be unprecedented in its scope, as we seek to address the outstanding questions about light scattering by marine particles as described in our Objectives above. Nearly all of the instruments, equipment and facilities to conduct this research program have already been developed at HOBI Labs. These include the HydroBeta, HydroScat-6, HydroScat-2, a-beta, c-beta, HydroRad and HydroDAS. Other commercial instrumentation that we have and will use in our research on this project include a Coulter Counter, spectrophotometer, PRR600, AC9, and CTD.

HydroBeta is unique among all ocean-optical instruments ever developed and incorporates many impressive capabilities important to gaining a more complete understanding of the VSF of ocean waters. This instrument is designed to measure the VSF at 11 angles simultaneously of ambient, undisturbed water. What's more, these angles can be set to any 11 angles in the range from 5 to 170 degrees in five-degree increments. With a sampling rate of $1 \mathrm{~Hz}$, the HydroBeta is easily used as a profiling instrument, allowing us to investigate the variability of the VSF throughout the water column concomitant with a full range of optical and physical water-property measurements.

Successfully developing a multi-angle VSF instrument is only the first, though quite difficult step in measuring the VSF of ocean waters. The next, though equally important step is the accurate calibration of the instrument. This latter step historically has been a controversial and unresolved issue, bringing into question all previously reported VSF measurements. Petzold, for example, used a purely analytical calibration technique that he himself acknowledged in his famous 1972 report contained many unresolved questions. More recent VSF makers and users of VSF instruments have attempted to use spherical particles and Mie theory calculations of the VSF to calibrate their measurements. The problems with this approach are myriad and this approach is far from being proven or accepted. We have developed a method for calibrating HydroBeta with a method that relies only on the Lambertian properties of a diffusely reflecting target. Errors in the Lambertian target assumption are at most a few percent. The method is similar to the thoroughly documented and well tested technique we developed for calibrating the HydroScat backscattering instruments [Maffione and Dana, 1997]. This method involves measuring each receivers response to a Lambertian target, illuminated by the instrument's light source, over the receivers complete field-of-view. The result is a complete, absolute, in-water calibration that involves a bare minimum of assumptions, all of which can be independently verified. 


\section{WORK COMPLETED}

Although this project is still in its first year, in the first three months we developed an integrated profiling system called HydroProfiler. This package incorporates numerous optical and other oceanographic instruments that are integrated into a highly sophisticated multi-instrument data integration system called HydroDAS developed by HOBI Labs. A picture of the HydroProfiler aboard the R/V Pt. Sur is shown in Figure 1. Thus far we have deployed the HydroProfiler on three separate cruises aboard the Pt. Sur in Monterey Bay, on a cruise aboard the Endeavor around LEO-15, and on a cruise aboard a U.S. Navy vessel in the Gulf of Mexico.

\section{RESULTS}

Since this project is in its first year, we are just beginning to analyze the data collected on four cruises we have conducted thus far. Figure 2 shows examples of the VSF measured with HydroBeta on our most recent cruise aboard the Pt. Sur in Monterey Bay. This figure shows the VSF at four selected depths in a single profile. It is worth mentioning that continuous profiles of the VSF have never before been measured. Note in this graph how the shape of the VSF changes between the surface layer and below the thermocline. The surface layer was dominated by biological particles as evidenced by fluorometer measurements with the HydroScat-2. Note also that in the near forward direction there is much less difference in the VSF shape, indicating that the primary changes in the VSF due to differences in particle composition are mainly over the wide angles.

\section{IMPACT/APPLICATIONS}

We expect that our measurements of the complete VSF will have an enormous impact on nearly all areas of optical oceanography. No measurements of the kind we plan to obtain have ever been made. Indeed, the nearest data of this type were obtained over 25 years ago. This lack of systematic and complete VSF measurements has greatly hampered our understanding of light scattering by marine particles, the testing and refinement of optical models, and the calibration of ocean-optical systems. Our extensive collection of optical property measurements in various coastal environments will be a critical aid in developing bio-geo-optical models of coastal waters.

\section{RELATED PROJECTS}

The research we are conducting on this project is closely related to the research we are conducting on two ONR DRI's, CoBOP and HyCODE. Both of these DRI's benefit from, and contribute to this project. Our DRI projects also involved the study of water optical properties and their effect on radiative transfer. Work being conducted at NAWC by Dr.'s Mike Contarino and Linda Mullen are also benefiting significantly from the results of this project. We anticipate that work being conducted at NRL-Stennis by Dr.'s Robert Arnone and Alan Weidemann will also benefit from our research.

\section{REFERENCES}

Dana, D.R., R.A. Maffione, and P.E. Coenen, 1998. A new instrument for measuring the backward scattering and absorption coefficients simultaneously, Ocean Optics XIV Proceedings, S.G. Ackleson, Editor. 
Maffione, R.A., and D.R. Dana, 1997. Instruments and methods for measuring the backwardscattering coefficient of ocean waters, Appl. Opt., 36, 6057-6067.

Dana, D.R., and R.A. Maffione, 2000. Hydrobeta: A New Instrument for Measuring the Volume Scattering Function from 10 To 170 Degrees In Situ, Ocean Optics XV Proceedings, S.G. Ackleson, Editor. 


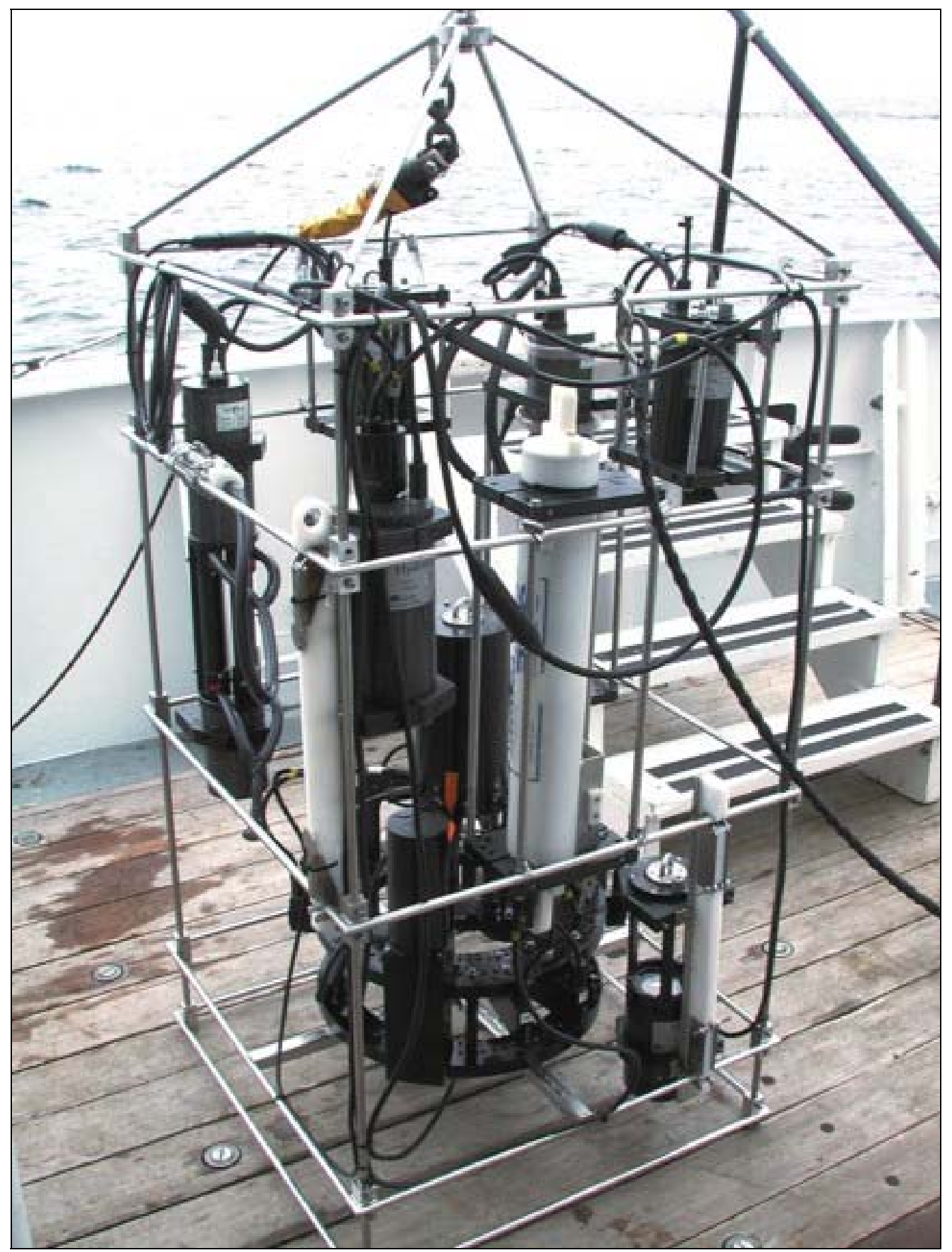

Figure 1. Photograph of the HydroProfiler aboard the R/V Pt. Sur. Instruments on this package include the HydroBeta, a-beta, c-beta, two HydroScat-2's, two AC9's, and a Seabird CTD. All instruments are integrated into a HydroDAS, a multi-instrument data integration system that collects data from all instruments and sends it up a two-conductor cable in real time while also supplying power to all the instruments. 




Figure 2. Graph of the VSF measured at four depths in a single profile in Monterey Bay with the HydroBeta. Note the significant difference in the shape of the VSF, especially in the back hemisphere, due to changes in the types of particles between the surface layer and interior. 